\title{
AS POSSIBILIDADES DA EXTENSÃO RURAL PELAS VIAS RADIOFÔNICAS: UMA ANÁLISE DO PROGRAMA PROSA RURAL
}

Maria Inês Gonçalves da Silva ${ }^{1}$

Marcelo Leles Romarco de Oliveira ${ }^{2}$

\begin{abstract}
RESUMO
Esse artigo busca refletir sobre o programa radiofônico Prosa Rural, produzido pela Empresa Brasileira de Pesquisa Agropecuária (Embrapa). As discussões perpassam pela análise do programa como ferramenta auxiliar junto aos serviços de Assistência Técnica e Extensão Rural (Ater), considerando que uma das atribuições do programa é atuar na promoção de informação e conhecimento no meio rural. A partir da análise documental e da escuta do programa foi possível identificar aspectos positivos no que diz respeito ao paralelo estabelecido entre o programa e os serviços de Ater: a escolha pelo rádio como instrumento de veiculação e o processo inicial participativo para construção do programa. Apesar disso, ao final do estudo, conclui-se que o programa não explora seus recursos de forma adequada e coerente com as perspectivas de Ater propostas pela política nacional, ou mesmo com os próprios objetivos do programa de priorização dos agricultores familiares nas programações. Sua estrutura de produção atual acaba por evidenciar somente os interesses da instituição em promover suas tecnologias, deixando a margem seu público principal, agricultores familiares.
\end{abstract}

Palavras-chaves: Comunicação rural, extensão rural, rádio.

\section{THE POSSIBILITIES OF RURAL EXTENSION THROUGH THE RADIOPHONIC WAYS: AN ANALYSIS OF THE RURAL PROSE PROGRAM}

\begin{abstract}
This article seeks to reflect about the radio program Prosa Rural, produced by the Brazilian Agricultural Research Corporation (Embrapa). The discussions are based on the analysis of the program as an tool auxiliary with the Technical Assistance and Rural Extension services (Ater), considering that one of the functions of the program is to improve the information and knowledge in the rural environment. Based on documentary analysis and listening to the program, it was possible to identify positive aspects regarding the parallel established between the program and Ater services: the choice of radio as an instrument for the placement and the initial participatory process for the construction of the program. Furthemore, at the end of study, it's possible concluded that the program doesn't discover your resources adequately and

${ }^{1}$ Graduada em Cooperativismo (UFV). Mestrado em Extensão Rural (UFV). E-mail: marysilvamigs@gmail.com

${ }^{2}$ Graduado em Administração (UFLA). Mestrado em Extensão Rural (UFV). Doutorado em Ciências Sociais em Desenvolvimento, Agricultura e Sociedade (UFRRJ). Professor do Programa de Pós-Graduação em Extensão Rural (PPGER/UFV). E-mail: marceloromarco@gmail.com
\end{abstract}


coherently with the Ater perspectives proposed by the national policy, and that will it finds the objectives of the family farmers prioritization program in the schedules. Its current production structure only evidence the interests of the institution in promoting its technologies, leaving the margin its main audience, family farmers.

keywords: Rural communication, rural extension, radio.

\section{INTRODUÇÃO}

Os serviços de Assistência Técnica e Extensão Rural (Ater) implantados na América Latina, a partir da Segunda Guerra Mundial, especificamente em 1948, com a implantação no estado de Minas Gerais da Associação de Crédito Assistência Rural (Acar), teve como referência o modelo estadunidense. Esse foi trazido ao Brasil pela American International Association for Economic and Social Development (AIA), agência norte americana fundada por Nelson Rockfeller. Nesse período, os serviços de Ater procuraram atuar junto as comunidades rurais para integrar ações de crédito supervisionado, difusão de tecnologia e assistência técnica e de mudança nos modos de vida. Os principais objetivos eram "educar" o homem do campo e mudar seu comportamento para que ele pudesse alcançar um melhor padrão de vida e que incorporasse novas tecnologias produtivas (SILVA, 2009).

A partir da década de 1960 os serviços de Ater passaram adotar estratégias metodológicas de intervenção baseadas nas teorias de Everett M. Rogers ou teorias difusionistas. Nessa perspectiva, os serviços eram pautados na difusão de técnicas, informações e práticas, cujo objetivo era mudar as atitudes dos agricultores e transformar o campo brasileiro. Entre as estratégias estavam a persuasão do público rural, considerando que o conhecimento partia de fontes exteriores à comunidade. Nesse sistema, os cientistas e técnicos formulavam as soluções dos problemas do campo e as difundiam para as comunidades rurais ou produtores rurais assistidos (FONSECA, 1985).

Crítico a essa visão etnocêntrica dos serviços de Ater, Paulo Freire (1983) se posicionou apontando que esse modelo de ação extensionista era danoso para os chamados receptores desse serviço, uma vez que se perpetuava relações de dependência desses com os técnicos extensionistas. Portanto, era necessário repensar métodos de abordagem que priorizassem processos de educação e comunicação, estabelecendo uma relação dialética entre agricultor e extensionista. Isso para que esses processos não se transformassem em meros instrumentos de dominação ou invasão cultural, e sim ferramentas de construção de conhecimento mútuo.

Dada essa visão dominante observada na ação extensionista dessa natureza, o Estado brasileiro passou a refletir, sobretudo nas duas últimas décadas, na proposição de novas estratégias que priorizassem o fortalecimento da agricultura familiar ${ }^{3}$, a preservação do meio ambiente, bem como o desenvolvimento sustentável, levando em consideração as necessidades de cada comunidade rural onde atuam os serviços de Ater (CAPORAL; RAMOS, 2006).

\footnotetext{
${ }^{3}$ Sobre a agricultura familiar podemos entender a partir das interpretações de Wanderley (2013) que este ator pratica uma forma de produção que predomina a integração entre gestão e trabalho, relações sociais e culturais. Nesse tipo de agricultura são os agricultores familiares que dirigem o processo produtivo, dando ênfase à diversificação e utilizando o trabalho familiar, eventualmente complementado pelo trabalho assalariado.
} 
A implementação da Política Nacional de Assistência Técnica e Extensão Rural (Pnater), construída a partir de 2003 e promulgada como Lei de Ater de no 12.188 em janeiro de 2010, trouxe mudanças significativas nos paradigmas da ação extensionista, uma vez que "a nova perspectiva exige que o extensionista seja um mediador de saberes e conhecimentos, um agente impulsionador do desenvolvimento das comunidades rurais que influi também nas mudanças institucionais que são necessárias nas entidades de Ater" (CAPORAL, RAMOS, 2006, p. 6).

Nesse sentido, tal política estabeleceu que os serviços de Ater fossem operacionalizados a partir de metodologias participativas e dialógicas, nas quais os técnicos atuariam como mediadores no processo educativo para busca do desenvolvimento rural sustentável. Prezando pelo resgate e valorização dos conhecimentos tradicionais da população rural na construção de saberes coletivos. Assim, de acordo com a Pnater, os serviços de Ater devem centralizar seus esforços no desenvolvimento rural sustentável e na agricultura familiar (BRASIL, 2004).

Nota-se, deste modo, uma proposição para mudanças significativas nos paradigmas da Extensão Rural, como a priorização do desenvolvimento rural sustentável, preocupação com a qualidade de vida dos agricultores e valorização dos conhecimentos da população rural, que antes eram ignorados em função do modelo linear de Extensão e difusão de tecnologias.

Nesse sentido, pode-se dizer que os avanços nas reflexões acerca do papel da Extensão Rural, entendendo o meio rural para além de um espaço exclusivo de produção agrícola, relações verticais e priorização de questões econômicas, bem como a institucionalização da política de Ater, veio a oferecer outras instruções teóricas para a prática extensionista. As mudanças propostas a partir dessa linha de pensamento, possivelmente, estimularam também as empresas ligadas não só diretamente a Ater, mas também, a transferência de tecnologia a pensarem em ações que materializassem essa nova perspectiva.

Dentre as principais empresas ligadas a difusão e transferência de tecnologias para o meio rural, encontra-se a Empresa Brasileira de Pesquisa Agropecuária - Embrapa vinculada ao Ministério da Agricultura, Pecuária e Abastecimento (MAPA). A Embrapa se destaca na difusão, transferência de tecnologias e transmissão de informações e conhecimentos no campo, cujo foco está, principalmente, na inovação tecnológica e produção e disseminação de conhecimento científico, mais próxima às diretrizes do difusionismo.

Entretanto, a Embrapa sinaliza, ao menos em tese, um esforço de adequação da sua política de transferência de tecnologias para com as novas perspectivas de Ater, desenhadas principalmente, nas duas últimas décadas. Essa guinada, tem como foco adequar as estratégias governamentais de apoio aos agricultores familiares, categoria essa que passa a ser reconhecida pelo Estado brasileiro, especialmente a partir da criação do Pronaf em meados da década de 1990. E, que tem seu protagonismo elevado a partir do primeiro governo do presidente Luís Inácio Lula da Silva. Nesse contexto, portanto, a Embrapa procura instituir instrumentos de diálogos e de aproximação junto a realidade desse público. No ano de 2004, é criado o programa de rádio intitulado Prosa Rural, na tentativa de levar aos agricultores familiares, os resultados das pesquisas de uma forma mais acessível e dialógica (MIÚRA, BELTRÃO, 2016) conforme os preceitos estabelecidos pela nova política de Extensão Rural.

Nesse sentido, este trabalho tem por objetivo realizar uma análise do programa de rádio Prosa Rural elaborado por uma instituição de grande importância na produção de conhecimentos científicos destinados ao meio rural, qual seja, a Embrapa. Pretende-se refletir como esse programa pode (ou não) se constituir em 
ferramenta alternativa para auxiliar nos processos de comunicação rural, contribuindo, ainda que de forma indireta, com os serviços de Ater, enquanto compartilhamento de conhecimentos e valorização da cultura rural.

\section{FUNDAMENTAÇÃO TEÓRICA: INTERSEÇÕES DA COMUNICAÇÃO E EXTENSÃO RURAL}

Acompanhando o modelo difusionista dos serviços de Ater, implantado principalmente a partir da década de 1960, pautado no extensionismo e funcionalismo, a Comunicação Rural brasileira era caracterizada pelos discursos unidirecionais e persuasivos. Isso porque o objetivo principal da teoria difusionista consistia em otimizar o tempo entre o lançamento de uma tecnologia e adoção dessa pelos agricultores. Nesse ciclo, a comunicação desempenhava um papel fundamental, atuando para garantir os processos de transferência de tecnologia. Considerando esse cenário, entende-se que se tratava muito mais de Informação Agrícola do que Comunicação Rural propriamente dita (BORDENAVE, 1983).

A partir da década 1980 começam a surgir outras perspectivas em detrimento da comunicação persuasiva vigente. Entre essas correntes de pensamentos podemos citar autores como Paulo Freire (1983) e Juan Bordenave (1983) que apresentaram métodos de abordagem que priorizaram processos de educação e comunicação, a partir de metodologias participativas. Freire (1983), refletindo sobre os processos de educação para o desenvolvimento humano, bem como sobre os trabalhos da Extensão enquanto processo educativo, discorreu sobre a necessidade de relações mais dialógicas, na quais os interlocutores caracterizassem-se como indivíduos semelhantes do ponto de vista da capacidade de compartilhar suas ideias de forma igualitária, uma vez que "na comunicação, não há sujeitos passivos", ou seja, a "educação é comunicação, é diálogo, na medida em que não é a transferência de saber, mas um encontro de sujeitos interlocutores que buscam a significação dos significados" (FREIRE, 1983 p.43-45).

Bordenave (1983, p.7) corrobora com essas reflexões ao conceituar a Comunicação Rural como um processo de troca e compartilhamento mútuo. Para o autor, trata-se de um "conjunto de fluxos de informação, de diálogo e de influência recíproca existentes entre os componentes do setor rural e entre eles e os demais setores da nação afetados pelo funcionamento da agricultura, ou interessados no melhoramento da vida rural". Dessa forma, a Comunicação Rural envolve os vários agentes sociais que compõem ou interagem com o meio rural. Essas considerações são importantes na medida em que a Comunicação Rural consiste em uma ferramenta fundamental para ação extensionista. Nessa perspectiva, o trabalho extensionista passaria pelo desafio de adaptar suas práticas a partir de uma comunicação mais dialógica, tendo ainda, desde a década de 1990, o auxílio das novas Tecnologias de Comunicação e Informação (TICs) inseridas no meio rural (SILVA; MÜLLER, 2015).

Cabe ressaltar, conforme mencionado anteriormente, que os serviços de Extensão Rural pública passam a ser orientados, a partir de 2004, pela Pnater, a qual propõe uma perspectiva de Ater alinhada com os valores, saberes e particularidades dos grupos atendidos por esse serviço. Dessa forma, tal política propõe a construção de relações entre agricultores e técnicos que sejam capazes de resgatar os conhecimentos locais e estimular a participação de todos os atores rurais nas mudanças necessárias nos níveis político, social, ambiental, econômico, cultural e ético.

A partir de então, a agricultura familiar e o desenvolvimento rural sustentável passam a receber especial atenção da Extensão Rural pública, 
conforme esclarecem os princípios básicos da Pnater: assegurar aos agricultores familiares e demais beneficiários dos programas do MDA acesso gratuito aos serviços de Ater; promoção do desenvolvimento rural sustentável; atuar com abordagem multidisciplinar e interdisciplinar direcionados pelos princípios da agroecologia; gestão democrática; desenvolver processos permanentes e continuados (BRASIL, 2004).

Nota-se que houve uma proposta de mudança significativa que influi diretamente na vida dos agricultores familiares. Castro e Pereira (2017) acreditam que a priorização das necessidades desses indivíduos pelos serviços de Ater se configura como uma mudança sensata, uma vez que os demais segmentos, médios e grandes produtores, possuem condições para arcar com os custos dos serviços privados. Ainda de acordo com os autores, tendo em vista a escassez de recursos dos serviços públicos é justo que esses se destinem aos agricultores menos capitalizados. Além disso, a produção agroecológica e gestão democrática preconizam uma agricultura mais sustentável e se adaptam melhor à realidade dos agricultores familiares.

Assim, se opondo ao modelo cartesiano antigo, na perspectiva preconizada pela Pnater, a relação entre técnicos de Ater e agricultores deve ser orientada pela troca mútua, valorização dos conhecimentos locais e construção de saberes conjuntos, tornando possível a transformação dos agricultores em agentes do seu próprio desenvolvimento (CAPORAL; RAMOS, 2006)

Coelho (2005, p.73-74) também faz crítica à ação extensionista baseada unicamente na difusão tecnológica. Para a autora, "num trabalho de orientação técnica efetiva, é exigido muito mais que a mera indicação da compra ou gestão de tecnologia", uma vez que "o impulso consumista dos insumos modernos, presente em toda sociedade, nem sempre pode levar ao sucesso na produção de alimentos". Coelho (2005) defende, ainda, a assistência técnica baseada em modelos de construção participativos, a partir de diálogos e reconhecimento dos saberes tradicionais da população rural enquanto contribuintes para elaboração de estratégias que solucionem os conflitos existentes na vida no campo.

Embora não se desconsidere a complexidade da atividade extensionista, bem como os vários processos que permeiam a Comunicação Rural, dentre as muitas responsabilidades atribuídas ao trabalho da Extensão, a atuação no acesso à informação e conhecimento por parte da população rural é de fundamental importância e o primeiro passo para construção do desenvolvimento rural. Desta forma, conforme Bordenave (1983), é importante atentar-se para que a Comunicação Rural, paralela aos trabalhos da Extensão, não tome um caráter enviesado, transformando-se em mera informação rural, levando apenas informações, ao invés de promover comunicação efetiva entre técnicos e população rural em geral.

O processo de troca e construção conjunta, através de uma comunicação dialógica é importante para que não se criem laços de dependência entre técnicos e agricultores. Diante dessas interseções entre a Comunicação Rural e Extensão Rural, bem como os avanços nos entendimentos das diretrizes que norteiam essas atividades, torna-se essencial pensar se tais mudanças estão sendo implementadas nas práticas.

\section{AS INCERTEZAS E RETROCESSOS DO ATUAL MOMENTO DA ATER}

Como este trabalho procura discutir a importância do rádio como instrumento de democratização de conhecimento para o campo através do debate no âmbito de ações de Ater, considera-se importante trazer uma breve reflexão do 
atual momento da Ater brasileira. No atual cenário, percebe-se avanços que ocorreram com a promulgação da Lei de Ater ํㅜ12.188, em 2010, consolidando uma "nova" Pnater, que na perspectiva de Caporal (2011, p. 24) "nasce com o estigma de ser responsável por um retrocesso no campo da Extensão Rural contemporânea". Contudo, em contraposição à política elaborada em 2004, a qual teve ampla participação da sociedade civil em um processo de construção democrático e participativo, na Pnater instituída pela lei de 2010, a participação popular foi menosprezada pelo governo federal. Nos últimos anos, identificou-se que as políticas voltadas para agricultura familiar vêm passando por processos de desmonte, inclusive no que se refere à oferta da Extensão Rural pública gratuita

Em 2013, disputas políticas internas e interesses, principalmente, da Confederação Nacional da Agricultura (CNA) pela apropriação da Extensão Rural, resultaram na criação da Agência Nacional de Assistência Técnica e Extensão Rural (Anater), através da Lei no. 12.897/2013 que autoriza a criação da Anater, e, que posteriormente foi instituída pelo Decreto no. 8.252/2014. Frente à pluralidade institucional dos serviços de ATER, a agência surge como forma de retornar à centralidade dos serviços à coordenação do Estado. Contudo, sua premissa reside no desenvolvimento da agricultura brasileira pela via da transferência tecnológica, retomando concepções de desenvolvimento baseadas na modernização da agricultura por meio do difusionismo.

Além do viés tecnológico produtivista, interpretando o campo como lugar exclusivo de produção, outras iniciativas da Anater traçam caminhos contrários à Pnater, como por exemplo, a inclusão de agricultores médios como beneficiários dos serviços de ATER públicos. Ademais, não há perspectivas de participação ou canais de escuta da sociedade civil e movimentos sociais interessados na Extensão Rural, visto que o decreto de criação da agência não prevê tais espaços de discussão e deliberação (ZARNOTT et al, 2015). Diante das modificações engendradas pela Anater, observa-se o retorno aos moldes difusionistas, dado pelo foco na transferência tecnológica, e ainda a negligência das conquistas advindas da política de Ater que foi construída a partir de um viés crítico e empoderador da agricultura familiar.

Cabe destacar também a centralidade da Empresa Brasileira de Pesquisa Agropecuária (Embrapa), na coordenação da Anater. Além de desfrutar de cadeiras no Conselho de Administração e na Diretoria Executiva, conforme expresso em lei, a Embrapa integra as competências da Anater no que refere à inovação tecnológica no campo, colaborando estreitamente para "promover a integração do sistema de pesquisa agropecuária e do sistema de assistência técnica e Extensão Rural, fomentar o aperfeiçoamento e a geração de novas tecnologias e a sua adoção pelos produtores" (BRASIL, 2013).

A Anater também sugere a transferência da centralidade da qualificação dos técnicos extensionistas do MDA para a Embrapa, por meio do Departamento de Transferência Tecnológica. Desta forma, além de negligenciar as diretrizes propostas pela Pnater, retornando ao método difusionista com foco na produção, percebe-se, ainda, ações equivocadas que não consideram as particularidades da agricultura familiar. A metodologia proposta para colocar em prática a orientação de transferência tecnológica que tem por inspiração o modelo já desenvolvido pela Embrapa, denominada "Treino \& Visita", caracteriza-se pela inadequação a realidade dos agricultores familiares, uma vez que não se adaptam a diversidade apresentada por essa categoria, e desconsideram, ainda, os conhecimentos tradicionais (ZARNOTT et al, 2015).

Vale lembrar que, assim como não integravam a agenda pública do governo federal até a década de 1990, os agricultores familiares também não faziam parte do 
público de interesse da Embrapa. Somente a partir de 1996, após o lançamento do Pronaf, os agricultores familiares foram inseridos nas pesquisas desta instituição. Contudo, conforme Bergamasco, Thomson e Borsatto (2017), o entusiasmo e dedicação para com a geração e transferência vertical de tecnologias compõem historicamente o foco das pesquisas da Embrapa. E essas, em sua maioria, contemplam uma parcela restrita de produtores rurais que possuem alto capital financeiro. Fato esse que sinaliza para incapacidade de desenvolver processos que contemplem a gestão participação, e capacitação de técnicos de ATER distanciados do caráter produtivista preconizados pela transferência tecnológica.

Em 2016 mais uma medida é tomada em oposição aos preceitos da agricultura familiar, quando o Governo Temer (2016-2019) extingue o MDA, transferindo para Casa Civil a administração das secretárias ligadas a reforma agrária $^{4}$. Com essa ação, as competências do MDA, passam para a Secretaria Especial de Agricultura Familiar e do Desenvolvimento Agrário (SEAD). O Conselho Nacional de Desenvolvimento Rural Sustentável (Condraf) se posiciona contra a medida, e em carta de repúdio afirma se tratar de "uma perda real, concreta, que representa retrocesso indiscutível para a pauta do desenvolvimento agrário e agrícola do Brasil". A extinção do MDA ocasiona o enfraquecimento institucional de negociação e pleito de propostas da agricultura familiar para o país, ao desconsiderar a importância dessa instituição.

Apesar do posicionamento dos movimentos sociais, o MDA permanece extinto do atual governo do presidente Jair Bolsonaro (2019-2023). Além disso, foi criada em 2 de janeiro de 2019, através do Decreto № 9.667, a Secretária de Agricultura Familiar e Cooperativismo, transferindo as competências da SEAD para o Ministério da Agricultura, Pecuária e Abastecimento (MAPA) (BRASIL, 2019).

Em fevereiro de 2020 com o Decreto no 10.253, o governo federal extingue - Departamento de Assistência Técnica e Extensão Rural (Dater) remodelando a estrutura de coordenação dos serviços de Extensão Rural que passa ser coordenado pelo Departamento de Desenvolvimento Comunitário, ligado ao Ministério da Agricultura Pecuária e Abastecimento (MAPA). Essa medida possivelmente, trará menor oferta de recursos e serviços de Ater o que impactará diretamente os agricultores familiares.

\section{MÉTODO}

Este trabalho tem por objeto de pesquisa o programa de rádio Prosa Rural, produzido pela Empresa Brasileira de Pesquisa Agropecuária (Embrapa). O programa foi idealizado no ano de 2003 e teve sua primeira transmissão em 2004, na região Nordeste. Atualmente é transmitido em todo território brasileiro com o objetivo de proporcionar o acesso a informações científicas e tecnológicas que sejam úteis no cotidiano dos agricultores familiares (MIÚRA; BELTRÃO, 2016). Nesse sentido, a proposta desse estudo permeou por refletir como o programa pode contribuir para os serviços de Ater, do ponto de vista do acesso à informação no campo.

O principal procedimento metodológico utilizado foi a pesquisa documental. Buscou-se reunir documentos oficiais da Embrapa que regem, atualmente, 0 funcionamento do Prosa Rural, tais como: manual de produção, edital de seleção dos temas, listagem da grade de programação, entre outros. Além disso, foram

\footnotetext{
${ }^{4}$ São elas: Secretaria Especial de Agricultura Familiar e do Desenvolvimento Agrário, Secretaria de Reordenamento Agrário, Secretaria da Agricultura Familiar, Secretaria de Desenvolvimento Territorial e Secretaria Extraordinária de Regularização Fundiária na Amazônia Legal (BRASIL, 2016).
} 
utilizadas informações disponibilizadas no portal oficial da instituição e a literatura disponível sobre o programa.

O estudo pautou-se na reflexão acerca do Prosa Rural, suas propostas de programação e diretrizes que norteiam o programa. A análise foi organizada conforme a metodologia de análise de conteúdo, proposta por Bardin (2011): (1) préanálise, que tem por objetivo organizar as ideias a partir da seleção do material de análise, formulação das hipóteses e indicadores para interpretação final; (2) exploração do material, que consiste na aplicação do planejamento na etapa anterior; e por fim (3) tratamento dos resultados obtidos e interpretação.

Nesse sentido, a primeira etapa tratou-se da coleta do material sobre o programa, através das fontes já citadas, e definição das categorias de análise. Ressalta-se que a seleção dos materiais foi realizada considerando o período mais recente, ano 2018. Dessa forma, utilizou-se as últimas versões publicadas de cada documento. Sendo assim, compôs o material de análise: $2^{\circ}$ edição do manual de produção do programa, publicado em 2016; edital de seleção de temas 2018, publicado em 2017; listagens da grade de programação de 2018; e demais informações gerais sobre o programa disponíveis no site oficial. Através desses documentos, bem como da literatura disponível, a proposta dedicou-se a investigar: o processo de surgimento e formulação do programa, o formato de apresentação atual, e a (in)adequação ao seu público principal, agricultores familiares.

A segunda etapa, tratando-se da aplicação da etapa anterior, foi realizada a partir desses três eixos. De forma complementar, para auxiliar na construção do olhar dos autores, fez-se a escuta de, aproximadamente, dez edições do programa, sendo selecionados aleatoriamente considerando o intervalo do primeiro semestre de 2018, ou seja, de janeiro a junho. Na sequência extraiu as informações de cada edição, com base nos seguintes aspectos: temas abrangidos pela discussão, formas de apresentação dos temas, características da linguagem utilizada, tanto pelos locutores quanto pelos participantes e abertura a participação dos agricultores familiares. Esses eixos de análise foram ainda estudados a partir de um olhar de correspondência ou distanciamento com as perspectivas da Política Nacional de Assistência Técnica e Extensão Rural (Pnater), a fim de refletir sobre as possibilidades de uma atuação conjunta em benefício da agricultura familiar.

Ressalta-se que toda programação encontra-se disponível no site do Prosa Rural, localizado no portal da Embrapa, no qual consta, ainda, áudios de todos programas já transmitidos disponíveis para download ${ }^{5}$. Por fim, na etapa final, o esforço passou por correlacionar as análises das categorias sobre o programa aos serviços de Ater, investigando sobre suas possíveis relações.

\section{RESULTADOS E DISCUSSÕES: O PROGRAMA PROSA RURAL}

Tendo em vista as discussões acerca da Extensão Rural, bem como sua relação com a Comunicação Rural anteriormente debatidos, nesta seção serão apresentadas reflexões acerca do objeto de estudo, o programa radiofônico Prosa Rural. Inicialmente, cabe apresentar o contexto de surgimento do programa.

Fundada em 26 de abril de 1973, a Embrapa caracteriza-se como uma empresa de inovação tecnológica, vinculada ao Ministério da Agricultura, Pecuária e Abastecimento (MAPA), tendo atualmente a missão de "fornecer soluções de pesquisa, desenvolvimento e inovação para a sustentabilidade da agricultura e para

\footnotetext{
5 Toda programação pode ser acessada através do portal oficial da Embrapa, no endereço eletrônico: https://www.embrapa.br/en/prosa-rural/
} 
o benefício da sociedade brasileira" (EMBRAPA, 20186). Nessa perspectiva, sua trajetória na comunicação teve como base as diretrizes do difusionismo.

Com a criação, em 1996, do Programa Nacional de Fortalecimento da Agricultura (Pronaf) ${ }^{7}$, e o reconhecimento por parte do Estado brasileiro da importância da agricultura familiar, a Embrapa passa dar mais atenção a essa categoria social. Em sua Política de Comunicação, criada nesse mesmo ano, a Empresa começa a pensar em estratégias de comunicação que abarcassem as demandas deste grupo. Contudo, somente após a atualização da referida política, em 2002, que ações mais concretas foram implementadas. Nesse contexto, reconhecendo a necessidade de utilização de ferramentas mais adequadas à diversidade dos seus públicos de interesse e no âmbito das políticas de valorização da agricultura familiar, a partir da colaboração nas políticas sociais e de desenvolvimento rural, inicialmente em linhas de ação do programa Fome Zero ${ }^{8}$, do Governo Federal, foi criado, em 2004, o programa de rádio Prosa Rural (BELTRÃO, 2010).

Em primeiro lugar, pontua-se que a própria configuração do programa escolhendo o rádio como meio de comunicação é positiva para disseminação de informação no meio rural, contribuindo com os serviços de Ater. Isso porque, conforme anteriormente salientado, faz parte das atribuições dos serviços de Ater atuar no acesso à informação e conhecimentos. Contudo, a desestruturação dos escritórios locais e o reduzido quadro de funcionários nestes serviços públicos ainda são problemas frequentes. Somados ao processo de desmonte nos anos de 1990 , que não se recuperou ao longo dos anos, a grave crise econômica no Brasil a partir de 2014, piorou a destinação dos recursos para as instituições públicas de Ater (CASTRO; PEREIRA, 2017). Dessa forma é possível refletir que essa modalidade de transferência de informações e conhecimento pode contribuir para mitigar um pouco essas consequências, ou seja, acredita-se que o rádio pode se configurar em alternativa interessante para auxiliar os serviços de Ater no que refere ao acesso à informação no campo.

Nesse debate, vale ressaltar as dificuldades do acesso à informação pelos rurícolas e como o rádio se insere nessa problemática de forma positiva. Conforme Vieira (2016), muitos são os ruídos que interferem na Comunicação Rural. Diversos fatores que caracterizam o meio rural acabam por se tornarem barreiras no acesso a informação:

\begin{abstract}
Muitas são as barreiras que interferem na comunicação e, na rural alguns ruídos se fazem mais presentes do que na comunicação urbana, não apenas baseados no nível de escolaridade e decodificação das mensagens por meio dos produtores rurais, mas sim com enfoque da ruralidade em si, dos ruídos sonoros específicos do campo, da linguagem detentora de códigos específicos, e limitações na inclusão digital, no sinal deficiente ou inexistente da comunicação de telefonia móvel e em determinadas regiões até mesmo da fixa. Enfim, na barreira geográfica que delimita a zona rural e distância o cidadão do campo das contemporâneas tecnologias mais presentes no ambiente urbano (VIEIRA, 2016, p. 24).
\end{abstract}

\footnotetext{
${ }^{6}$ A missão, visão e valores da instituição encontra-se disponíveis no site: https://www.embrapa.br/en/missaovisao-e-valores

7 Programa que é fruto das lutas e reivindicações do movimento sindical dos trabalhadores rurais que lutavam por algum amparo do Estado em defesa dos agricultores familiares

8 O Fome Zero refere-se a um programa do Governo Federal, instituído em 2003, durante o mandato do presidente Luiz Inácio Lula da Silva, visando garantir o direito de alimentação da população brasileira.
} 
Nesse contexto, chama-se a atenção para a potencialidade do rádio no enfrentamento das barreiras acima apontadas. Escobar e Miúra (2008) corroboram com essa afirmação ao discorrerem sobre a importância desse meio de comunicação na áreas rurais. Segundo as autoras, apesar dos avanços dos aparatos tecnológicos dos meios de comunicação para além das áreas urbanas, o rádio é ainda um meio de comunicação popular nas áreas rurais. Isso porque essa ferramenta pode auxiliar nas dificuldades de obtenção de informação à medida que se caracteriza como meio de comunicação de fácil acesso pela maior parte da população, incluindo as de baixa renda ou moradores de áreas mais remotas. Além disso contempla todas as classes sociais e não exige grau de escolaridade.

Ainda acerca da importância do rádio como meio de comunicação no campo, Fraga (2018) traz apontamentos mais recentes sobre o espaço que o mesmo ocupa no cotidiano dos rurícolas. De acordo com sua pesquisa, esse meio de comunicação se mantém presente nos domicílios dos brasileiros. A partir da utilização de dados secundários da pesquisa "TIC Domicílios 2016", a pesquisadora constatou que, mesmo diante do crescente acesso às Tecnologias de Informação e Comunicação (TIC) pela população, os meios de comunicação tradicionais, como rádio e televisão, ainda se fazem presente tanto no meio rural quanto no urbano. Conforme a pesquisa, até o ano de 2016 , o rádio estava presente em $63 \%$ dos domicílios rurais.

Portanto, tendo em vista essas informações, é possível afirmar que o Prosa Rural apresenta desde sua concepção potencialidade para colaborar, em certa medida, com a ação extensionista do ponto de vista do acesso à informação, uma vez que optou por um meio de comunicação popular nas áreas rurais.

Outro aspecto interessante diz respeito ao público principal do programa. A priorização de agricultores familiares, ao menos no que diz respeito a sua idealização, como público principal também corrobora com as perspectivas da política de Ater que propõe a priorização e o fortalecimento dessa categoria socioprofissional. Cabe então refletir sobre a trajetória do programa e sua realidade nos dias atuais, investigando se existe ou não um diálogo com a Extensão Rural.

Para a implementação inicial foi realizado pela Embrapa um diagnóstico pela antropóloga Maria do Socorro de Magalhães e pelo cinegrafista e fotógrafo Olavo Maciel. O trabalho se desenvolveu por meio da aplicação de um questionário semiestruturado, além de entrevistas, abrangendo na ocasião seis estados do Semiárido (Alagoas, Bahia, Ceará, Paraíba, Pernambuco e Piauí). Foram entrevistadas 267 pessoas, entre elas lideranças locais, técnicos, agricultores, estudantes, donas de casa, entre outros (MIURA, BELTRÃO, 2016).

Esse estudo contribuiu para levantar os aspectos importantes a serem considerados na formulação do programa para que pudesse alinhar as pesquisas desenvolvidas pela Embrapa às necessidades e lacunas identificadas de forma a contemplar seu público principal, agricultores familiares do semiárido nordestino (MIURA, BELTRÃO, 2016). A partir desse diagnóstico, bem como de outras iniciativas internas da Embrapa, como reuniões entre pesquisadores e coordenadores da instituição para debater a proposta, tem início o Prosa Rural, sob coordenação da Embrapa Informação Tecnológica.

Sua idealização data o ano de 2003, mas sua primeira transmissão ocorreu já em 2004. O surgimento do programa se deu como um espaço de divulgação de tecnologias e outras informações para famílias rurais do semiárido nordestino com o intuito de promover a difusão de informação e cultura a partir de uma programação em formato de prosa entre apresentadores e participantes. Em seus primórdios era transmitido por apenas 50 emissoras de rádio. Sua expansão se deu de forma 
acelerada, totalizando 423 rádios parceiras ainda no ano de 2004. No ano seguinte, o programa atingiu outras regiões como Norte e Vale do Jequitinhonha, em Minas Gerais. Posteriormente, de 2006 a 2008, ampliou-se para as regiões centro-oeste, sudeste e sul (EMBRAPA, 2019).

Em 2018, conforme apontam registros do site da instituição, o Prosa Rural era transmitido por mais de 1000 rádios parceiras em todo Brasil. As programações são divididas em quatro grades regionais com programações distintas. São elas: Região Norte, Região Nordeste e Vale do Jequitinhonha, Região CentroOeste/Sudeste e Região Sul. Pontua-se assim, que as programações da região Centro-Oeste são agrupadas com a região Sudeste, e o vale do Jequitinhonha recebe a mesma programação destinada a região Nordeste. Para cada grade regional são produzidos 48 programas anuais, transmitidos semanalmente com duração de 15 minutos, além dos programas especiais criados em faixas extras, os quais as rádios podem veicular no dia e horário que desejarem. Destaca-se ainda que a veiculação do programa é gratuita, sendo distribuída pela instituição para as rádios parceiras, além de disponibilizar no site os programas gravados (EMBRAPA, 2018).

Para fazer a transmissão basta as rádios realizarem seu cadastro no Sistema de Informações Gerencias do Prosa Rural - (SIG-Prosa Rural), localizado no site do programa. Através desse registro, as emissoras têm acesso aos downloads dos áudios em resolução de 128 kbps para veicularem nos horários que Ihe forem mais convenientes. Podem ainda os reprisar quantas vezes desejarem em diferentes ocasiões (EMBRAPA, 2018).

Percebe-se assim que o programa surge a partir de uma construção coletiva e democrática, muito embora isso não se mantenha ao longo de sua existência, conforme veremos mais adiante. A iniciativa da instituição em consultar o público através do diagnóstico acerca das suas necessidades, lacunas e desejos para construção do formato do programa pode sinalizar para uma preocupação com os principais públicos ouvintes do programa (jovens e agricultores familiares), buscando através de um processo participativo a construção do desenvolvimento rural. Além disso, a disponibilidade de transmissão por meio das rádios parceiras que possuem acesso gratuito e facilitado, contribuem para que as informações possam chegar aos agricultores de todas as regiões, mesmo aqueles que residem em locais mais remotos ou de difícil acesso, sem nenhum custo para os mesmos.

De forma geral, podemos então associar os esforços de construção do programa às perspectivas de Extensão Rural voltadas ao bem-estar do agricultor, indo ao encontro das reflexões de Caporal e Ramos (2006), que acreditam na importância da participação e do diálogo junto aos agricultores. No caso do Prosa Rural, seus produtores procuraram, no processo inicial, envolver os agricultores na construção do programa, além de possibilitar $o$ acesso à informação e conhecimentos, abrindo caminhos para que a população rural possa escolher quais técnicas desejariam utilizar.

No que se refere a produção de quatro grades distintas, segundo informações do site, essa organização se deve à preocupação com a diversidade local, procurando criar programações que mais se assemelhem à realidade de cada região, além de promover artistas e as culturas locais. A estrutura do programa também é exaltada no manual de produção do mesmo, conforme pode ser observado na descrição dos seus objetivos:

O Prosa Rural divulga a pesquisa científica e tecnológica. Ele leva os resultados da pesquisa científica em linguagem fácil e regionalizada para o público, difundindo tecnologias que 
possam ser aplicadas nas propriedades rurais. Além disso, divulga a cultura local, na forma de cordel, música, conto, poesia e radiodrama. O Prosa Rural busca contribuir para a democratização do acesso às informações tecnológicas e conhecimentos gerados pela ciência. Assim, procura fortalecer a população rural e despertar o intercâmbio entre o saber científico e o saber do campo, e vice-versa (MIÚRA; BELTRÃO, 2016, p.30).

Apesar desses apontamentos, vale lembrar a heterogeneidade e extensão do território brasileiro, o que provavelmente inviabiliza programações pontuais para cada região. Outros aspectos como diferenças culturais, costumes e linguagens regionalizadas, certamente, também não encontram espaço para serem contempladas em sua totalidade, como anseiam e afirmam os idealizadores do programa.

Questiona-se, ainda, a afirmação da utilização de uma linguagem simples e regionalizada. Conforme apontado no trecho acima, o programa se desenvolve a partir de uma linguagem simples e coloquial. Além disso, faz-se o uso de vocabulário descontraído, analogias e dramatizações, e assim cria-se um clima de proximidade com o cotidiano do agricultor (MIURA, BELTRÃO, 2016). Essas pontuações puderam ser observadas no diálogo entre os locutores que procuram inserir os ouvintes na dinâmica com falas diretas, além do uso de situações corriqueiras no cotidiano dos rurais para introduzir de forma mais leve e descontraída os conteúdos.

Contudo, para além do diálogo entre os dois locutores, se tratando de um homem e uma mulher, o programa é organizado em quadros que trazem interações com técnicos, pesquisadores e produtores rurais diversos. Desta forma, ao ouvir as edições, foi possível observar que a utilização de uma linguagem simples não acontece de forma contínua, durante as interações são usados vários termos técnicos que nem sempre são de fácil compreensão. A dificuldade em adequar o saber científico para uma linguagem mais popularizada é eminente. $O$ caráter científico encontra-se enraizado nas falas dos técnicos da Embrapa que participam dos quadros concedendo entrevistas ou discorrendo sobre o tema. Esses, em sua maioria, apresentam um vocabulário mais carregado que, embora presente em espaço acadêmico e científico, não é comum no cotidiano, sobretudo no meio rural onde os índices de escolaridade são mais baixos ${ }^{9}$.

Chama-se atenção, ainda, para o curto espaço de tempo do programa e, portanto, das participações, que são comprimidas em menos de cinco minutos de duração. Assim, em alguns casos percebe-se que essa limitação acaba por comprometer a comunicação com os ouvintes do ponto de vista de entendimento, principalmente quando se trata de temas que envolvem determinada complexidade. As falas rápidas, somadas ao uso de frases mais longas, dificultam a compressão do conteúdo debatido. Como forma de atenuar essas problemáticas, observou-se que nesses casos, os locutores repetem as principais informações com frases mais pontuais e vocabulário mais simples.

O programa, conforme constatado pela escuta, se guia por um tema principal a cada edição, o qual abordará alguma tecnologia ou conhecimento científico produzido pela Embrapa. As informações sobre estudos atuais acerca do tema abordado são trazidas no quadro Um dedo de prosa, no qual são realizadas

\footnotetext{
${ }^{9}$ Segundo dados do Relatório Anuário Brasileiro de Educação Básica 2018, o rural brasileiro tinha, em 2015, apenas $82,3 \%$ da população de 15 anos ou mais alfabetizada. Além disso a escolaridade média dos residentes rurais de 18 a 29 anos é bem inferior a urbana da mesma faixa etária. A primeira apresenta índice de 8,3 anos de estudo, enquanto a população urbana atinge seus 10,3 anos de estudo (PNAD, 2018).
} 
entrevistas breves com especialistas na tecnologia a ser divulgada. O quadro Pitacos da hora trata-se de um espaço com dicas em geral, buscando destacar algo sobre a tecnologia apresentada, trazendo uma abordagem mais prática. Há também interação com agricultores que realizam a atividade tema, os quais contam suas experiências no quadro Fala Produtor. O Receitas do Prosa, segundo idealizares procura integrar o público feminino, o qual possui pouco espaço no meio radiofônico, apresentando uma opção de receitas que utilizam os ingredientes associados à tecnologia em foco. Favas Contadas objetiva promover a história, cultura e tradições, dando espaço aos artistas locais para exporem seus trabalhos, como músicas, poesias, cordéis, entre outros. Por fim, Ao Pé do Ouvido traz informações sobre campanhas de utilidade pública. (MIÚRA; BELTRÃO, 2016).

Pontua-se que os quadros são usados de acordo com a necessidade de cada programa, não aparecendo obrigatoriamente em todas as edições. A partir dessa estrutura de organização é possível observar uma diversidade de interações trazidas pelo programa, embora seja limitado pelo tempo de duração, esse produto midiático procura se organizar de forma a abranger diversos aspectos e atores na discussão do programa. De forma geral, foi observado que os quatro primeiros quadros têm por foco a tecnologia/atividade proposta naquela edição. Porém, cada quadro tem seu objetivo específico diante do tema, trazendo informações e interações distintas. Pode-se dizer que são complementares e possivelmente contribuem para um melhor entendimento por parte do público ouvinte, visto trazer variados pontos de vistas no decorrer do programa. Já os dois últimos possuem um viés mais comunitário, com assuntos gerais, menos centrados da divulgação de conhecimentos científicos, mas não menos relevantes aos ouvintes.

Nesse sentido, não se pode negar a relevância do Prosa Rural no que diz respeito a facilitação do acesso à informação a população rural ouvinte, contribuindo com a divulgação de tecnologias e conhecimento científico para o campo. Corroboram com essa perspectiva Escobar e Miúra (2008) ao apontarem que o programa visa levar conhecimento a sociedade rural, atuando como disseminador de informação técnico-científica, sem desconsiderar, contudo, os saberes do homem rural, visto acreditar que essa junção contribui para as representações sociais e melhoria na qualidade de vida dos indivíduos.

Contudo, alguns aspectos são questionáveis na definição do que será contemplado como tema do programa, apresentando características que vão no caminho contrário ao apontado por esses autores. Os temas, atualmente, são definidos através de edital específico lançado pela instituição para selecionar propostas de pautas. Esse documento limita não somente a participação direta dos agricultores ouvintes na definição da grade de temas, interrompendo o processo participativo que existiu no surgimento do programa, como também restringe os temas às tecnologias produzidas pela instituição. Serve para ilustrar o edital de 2018 para formulação da grade 2018 , no qual podemos observar essas restrições no item "Dos requisitos":

\section{DOS REQUISITOS}

2.1 Qualquer pesquisador ou técnico de nível superior da Embrapa, ou de instituição parceira, poderá apresentar propostas de tema para a produção de matéria a ser veiculada na grade 2018 de programação do Prosa Rural. 2.2 Somente poderão ser propostos como temas de programas do Prosa Rural 2018 tecnologias, produtos e processos (TPP) desenvolvidos pela Embrapa, ou por instituição parceira, cujos resultados estejam validados por instâncias técnicas da proponente (tais como Comitês Técnicos Internos ou outras 
que a Unidade/Instituição dispor) e direcionados às necessidades do público-alvo do programa (INFORMAÇÃO TECNOLÓGICA, 2017, p. 1).

Portanto, verifica-se uma limitação às proposições que podem de certa forma interferir no processo de sugestões dos agricultores familiares. Ainda que eles participem e levem suas sugestões para as Unidades da instituição, não há garantias de que terão suas demandas, de fato, atendidas. Além disso, as propostas terão de ser adaptadas às tecnologias, produtos e processos desenvolvidos pela Embrapa, estrutura a qual acaba por reafirmar o "dirigismo de tecnologias e o controle das informações que caracterizam a prática tradicional difusionista" (BELTRÃO, 2010, p.139).

A determinação do referido documento sobre a abordagem de tecnologias produzidas pela Embrapa nas programações acarreta, ainda, na desvalorização dos conhecimentos tradicionais da população rural, visto que não encontram espaço no programa. Isso porque o programa aborda somente temas que contemplem, de alguma forma, pesquisa e tecnologias da própria Embrapa. Portanto, apenas terão espaço dentro do programa no quadro Fala Produtor, por exemplo, aqueles agricultores que já fazem usos tecnologias mencionadas, já que se trata de relatos de experiências relacionadas ao tema.

Diante do exposto, percebe-se forte inclinação do programa para disseminação de tecnologia e processos técnicos, observados também através da listagem de temas, que em sua maioria abordam questões de ordem produtiva. As exigências apresentadas no edital, citadas anteriormente, acarretam no risco de transformar o programa em mero disseminador de tecnologia e processos técnicos. Embora a instituição afirme uma preocupação em priorizar temas que contemplem a agricultura familiar (EMBRAPA, 2018), sua estrutura centralizada de definição dos temas, acaba por reduzir o programa a divulgação da produção cientifica da empresa. Tal fato sugere o uso desse canal com vistas a sua promoção institucional, ou seja, percebe-se uma inclinação para manutenção da marca, principalmente diante do "novo" público, a agricultura familiar, visto ser o primeiro canal de comunicação da instituição dedicado a essa categoria.

Ressalta-se, ainda, a forma de planejamento dos temas do programa, os quais são definidos, anualmente. Dessa forma, fica determinada desde o primeiro mês de cada ano, toda grade de temas que será transmitido ao longo do ano. Acredita-se que essa maneira de organização possa enrijecer a estrutura do programa, pois acaba por impedir a reestruturação de acordo com as demandas eventuais durante o ano, ou mesmo mudanças climáticas, desastres ambientais que afetem o cotidiano dos agricultores, descoberta de novas tecnologias importantes naquela época específica, coerência com políticas públicas, entre outras.

A programação anual também reforça o foco dado a divulgação da Embrapa, através de uma estrutura rígida que impede o diálogo com questões atuais. Além disso, tais posicionamentos verticais da escolha dos temas apõem-se as propostas de intervenções da Pnater que prezam por ações democráticas e participativas. Flexibilizar a programação para acontecimentos ao longo do ano talvez possa contribuir de forma mais satisfatória para os serviços de Ater, trazendo informações mais recentes e condizentes com as dificuldades enfrentadas naquele determinado momento.

Em suma, percebe-se que o Prosa Rural possui potencialidades interessantes para atuar em paralelo com serviços de Ater, em benefício dos agricultores familiares. Contudo, as limitações observadas em sua forma de estruturação e desenvolvimento que impedem a participação dos agricultores 
familiares, nos mostra certo desiquilíbrio entre a democratização da ciência e priorização dos interesses da empresa. Para adequação às perspectivas de Extensão Rural ancoradas na Pnater, algumas reestruturações precisariam ser feitas.

\section{CONSIDERAÇÕES FINAIS}

A análise do Prosa Rural a partir da perspectiva de contribuições e alinhamento com os serviços de Ater nos permite, ao fim, refletir que o programa apresenta alguns aspectos positivos que devem ser ressaltados: a escolha pelo rádio como meio de veiculação das pesquisas científicas voltadas ao rural é interessante a medida que esse instrumento possui características particulares que o mantém presente no cotidiano das famílias rurais até os dias atuais; O processo de construção inicial do programa se deu de forma coletiva e participativa, a partir do diagnóstico com a população rural a quem se destina o programa, buscando identificar seus interesses e necessidades.

Contudo, o programa se distancia, ao longo de sua trajetória, das perspectivas dos serviços de Ater propostas pela política nacional, e do próprio objetivo de priorização de agricultores familiares em suas programações. Apesar de seu potencial do ponto de vista do acesso a informação, o programa prioriza a difusão tecnológica da empresa de forma evidente, em detrimento da participação dos agricultores que não encontram espaço no programa.

Percebe-se os esforços pela utilização de uma linguagem simples, no entanto, eles se mostram limitados pela dificuldade de adaptação dos resultados das pesquisas científicas a um vocabulário acessível em sua totalidade, principalmente observados nas falas dos técnicos da empresa. A tentativa de adequação dos temas a partir de grades regionalizadas também sofre limitações do ponto de vista da amplitude e diversidade do território brasileiro. Além disso, a composição da grade de temas é definida por meio de edital restrito aos setores da instituição produtora do programa ou parceiros, impedindo a participação dos agricultores familiares, tendo ainda a obrigatoriedade dos temas em abordarem alguma tecnologia, produto ou processo desenvolvidos pela Embrapa.

Assim, o processo de construção e desenvolvimento do programa acontece de forma centralizada, afastando-se da proposta inicial que promovia o envolvimento do setor agrícola familiar na dinâmica de formulação do programa. Portanto, as questões referentes à falta de participação vão na contramão da proposta de trabalho extensionista sob direção da Pnater, que prezam por metodologias participativas. Nesse aspecto fica evidente o foco da Embrapa na difusão e transmissão de informações e conhecimentos a partir de uma perspectiva vertical. A empresa se coloca no comando tanto da construção quanto no desenvolvimento do programa, desconsiderando participações externas.

A programação anual também pode deixar a desejar no que diz respeito a adequação do cotidiano dos ouvintes, eventuais mudanças climáticas que podem afetar na produção, coerência com novas políticas públicas, entre outros aspectos.

Diante dessas reflexões, conclui-se que o Prosa Rural tem potencial para atuar em conjunto com os serviços de Ater, visto dar suporte aos técnicos e a população rural ouvinte no que diz respeito ao acesso a informação de forma fácil e prática, através de um meio de comunicação popular no meio rural. Tendo em vista as dificuldades enfrentadas pelos técnicos dada diminuição dos recursos destinados a Extensão Rural pública, e ainda, as barreiras que dificultam a Comunicação Rural, esse programa radiofônico poderia, se melhor articulado com as perspectivas da Pnater, gerar contribuições interessantes na busca do desenvolvimento rural. 
Contudo, a realidade atual do programa aponta para priorização dos interesses da instituição em promover suas tecnologias, deixando à margem seu público principal, agricultores familiares. Ao longo de sua existência, o programa perdeu sua proposta inicial de construção participativa. Sua estrutura tornou-se centralizada e com certa rigidez que acaba por minar a participação dos agricultores familiares.

Por fim entende-se que a extensão rural atravessa momentos de desmontes e incertezas, caracterizando-se como objeto de disputa e apresentando incoerências até mesmo nas políticas públicas em apoio à agricultura familiar, espera-se que as conquistas inerentes a Pnater, resultado das reflexões críticas as perspectivas verticais e autoritária que conduziram os serviços de ATER durante anos, bem como da participação dos movimentos sociais pela luta ao reconhecimento da categoria agricultura familiar, permaneçam como direção das atividades extensionistas.

Para tanto, é necessário fomentar ações orientadas pela perspectiva de educação e comunicação pautadas nas relações dialógicas devem ser priorizadas. Sendo, portanto, necessário considerar a complexidade que envolve o universo da Extensão Rural, ou mesmo os vários processos que permeiam a comunicação rural, a atuação conjunta em prol do acesso à informação e conhecimento com vistas a educação dialógica se estabelece, portanto, um como caminho possível na direção ao desenvolvimento rural.

\section{AGRADECIMENTOS}

O presente trabalho foi realizado com apoio da Coordenação de Aperfeiçoamento de Pessoal de Nível Superior - Brasil (CAPES) - Código de Financiamento 001. Agradecemos à CAPES.

\section{REFERÊNCIAS}

BARDIN, L. Análise de conteúdo. Tradução Luís Antero Reto, Augusto Pinheiro. São Paulo: Edições 70, 2011.

BELTRÃO, S. L. L. A construção do diálogo interinstitucional para o desenvolvimento territorial rural sustentável: estratégias comunicativas e de participação no Território do Sisal, Bahia. Brasília, DF, 2010. 212p. Dissertação de mestrado. Centro de Desenvolvimento Sustentável, Universidade de Brasília.

BERGAMASCO, S. M. P. P; THOMSON, C. R; B, R S. Da extinção da Embrater à criação da Anater: os desafios da política de assistência técnica e extensão rural brasileira. p.314-342. In: DELGADO, G; C; BERGAMASCO, S. M. P. P. Agricultura Familiar brasileira: desafios e perspectivas de futuro. Secretária Especial de Agricultura e do Desenvolvimento Agrário, Brasília-DF, 2017.

BORDENAVE, J. E. D. O que é comunicação rural? São Paulo: Editora Brasiliense, 1983.

BRASIL. Lei $n .-12.897$, de 18 de dezembro de 2013. Autoriza o Poder Executivo federal a instituir serviço social autônomo denominado Agência Nacional de Assistência Técnica e Extensão Rural - ANATER e dá outras providências. Disponível em: http://www.planalto.gov.br/ccivil_03/_Ato20112014/2013/Lei/L12897.htm. Acesso em: 25 ago. 2020. 
BRASIL. Decreto no 10.253, de 20 de fevereiro de 2020 Aprova a Estrutura Regimental e o Quadro Demonstrativo dos Cargos em Comissão e das Funções de Confiança do Ministério da Agricultura, Pecuária e Abastecimento e remaneja e transforma cargos em comissão e funções de confiança. Diário Oficial da União, Órgão: Atos do Poder Executivo. Seção: 1 Brasília, DF, Edição: 37: página:7, 21 fev. 2020.

BRASIL. Ministério do Desenvolvimento Agrário. Política Nacional de Assistência Técnica e Extensão Rural. Brasília, DF: SAF; Dater, 2004.

CAPORAL, F. R. Lei de ATER: exclusão da Agroecologia e outras armadilhas. Caderno de Agroecologia, v. 6, n.2, p.23-33, set./dez. 2011.

CAPORAL, F; RAMOS, L. F. Da Extensão Rural convencional à Extensão Rural para o desenvolvimento sustentável: enfrentar desafios para romper a inércia Brasília, 2006.

CASTRO, C. N.; PEREIRA, C. N. Agricultura Familiar, Assistência Técnica e Extensão Rural e a política nacional de Ater. Instituto de Pesquisa Econômica Aplicada - Ipea. Texto para discussão 2343, Brasília, outubro, 2017.

COELHO, F. M. G. A arte das orientações técnicas no campo: concepções e métodos. Viçosa, MG: Ed. UFV, 2005139 p.

EMBRAPA. Empresa Brasileira de Pesquisa Agropecuária. Prosa Rural. [Home page]. Disponível em: https://www.embrapa.br/en/prosa-rural. Acesso em: 24 de maio de 2018.

ESCOBAR, J. L. MIÚRA, J. Pesquisa de Recepção do Programa de Rádio Prosa Rural: propondo uma metodologia. In: XXXI Congresso Brasileiro de Ciências da Comunicação., XXXI,. 2008, Natal. Anais... Natal: INTERCOM, 2008.

FONSECA, M. T. L. A Extensão Rural no Brasil, um projeto educativo para o capital. São Paulo: Edições Loyola, 1985. 193p.

FRAGA, K. L. O rural em rede: rádio, midiatização e ruralidade no cotidiano da Zona da Mata mineira. Viçosa, 2018. Tese (Doutorado em Extensão Rural). Universidade Federal de Viçosa, Viçosa- MG.

FREIRE, P. Extensão ou Comunicação. Rio de Janeiro: Paz e Terra, 1983. 93 p.

INFORMAÇÃO TECNOLÓGICA, Embrapa. Edital Seleção de propostas de temas para a produção da grade $\mathbf{2 0 1 8}$ do programa radiofônico Prosa Rural. Embrapa, 2017.

http://www.sct.embrapa.br/prosa_programas/Edital_Prosa_Rural_2018.pdf. Acesso em: 22 maio 2018.

MIURA, J.; BELTRÃO, S. L. L. Prosa Rural: Manual de Produção e Edição. 2. ed. Brasília, DF: Embrapa, 2016. 
OLIVEIRA, V. C. Industria Cultural e meio rural. Revista Mediação. Belo Horizonte, v.14, n14. jan./jun. 2012.

PEREIRA, F. A. "Velhas" ferramentas e "novos" arranjos para a universalização da acesso à informação - Prosa Rural e Minibibliotecas. Brasília, 2009. 138p. Dissertação de mestrado. Centro de Desenvolvimento Sustentável, Universidade de Brasília, Brasília.

PNAD. Pesquisa Nacional por Amostra de Domicílios. Anuário Brasileiro da Educação Básica. Pnad Contínua, Editora Moderna, 2018.

SILVA, C. M. da. Agricultura e Cooperação Internacional: a atuação da American Internacional Association for Economic and Social Development (AIA) e os programas de modernização no Brasil (1946-1961). 2009. 226p. Tese de doutorado em História da Ciência e da Saúde. FIOCRUZ.

SILVA, N. G.; MÜLLER, L. Comunicação rural: evolução x potencialidades. Revista Eletrônica em Gestão, Educação e Tecnologia Ambiental, Santa Maria. v.19, n.1. jan./abr. 2015, p.121-128.

VIEIRA, S. C. O papel do extensionista no fluxo bilateral de informações entre pesquisadores do agronegócio e produtores rurais. Tupã, 2016. 153p. Dissertação (Mestrado em Agronegócio e desenvolvimento). Universidade Estadual Paulista "Júlio Mesquita Filho", Tupã-Sp.

WANDERLEY, M. N. B. Agricultura familiar e campesinato: rupturas e continuidade. Rio de Janeiro. Estudos Sociedade e Agricultura, n. 21, p. 42-62, 2013.

ZARNOTT, A. V.; DALBIANCO, V. P.; NEÜMANN, P. S.; FIALHO, M. A. V. Avanços e retrocessos nas políticas de extensão rural: análise crítica sobre a Anater. In: $53^{\circ}$ CONGRESSO DA SOCIEDADE BRASILEIRA DE ECONOMIA, ADMINISTRAÇÃO E SOCIOLOGIA RURAL, 53., 2015, João Pessoa. Anais... João Pessoa: UFPB, 2015. 